\title{
Integrated management systems as a driver for sustainability: the review and analysis of the literature and the proposition of the conceptual framework
}

\author{
Jeniffer de Nadae ${ }^{\mathrm{a} *}$ (D), Marly Monteiro de Carvalho ${ }^{\mathrm{b}}$ \\ anniversidade Federal do Cariri - UFCA, Juazeiro do Norte, CE, Brasil

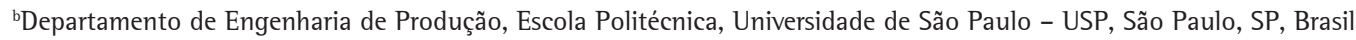 \\ *nadae.jeniffer@usp.br
}

\begin{abstract}
Paper aims: This paper aims to analyze the literature on standard management systems (ISO 14001, OHSAS 18001, SA 8000 , and $1 S 0$ 26000), and to propose a conceptual framework relating these standards to sustainability (based on TBL) to help answer the following research question: How does the literature address IMS and sustainability based on TBL?

Originality: This research sheds light on controversies, discussed in the literature, concerning the effects of IMS with sustainability standards.

Research method: The methodological approach used is a systematic literature review based on bibliometric theory and social network analysis. A conceptual model is presented, linking the main constructs, variables, and their relations to better understand the role of IMS as a driver for sustainability.

Main findings: Briefly, results show that more research is needed on the social dimension of Triple Bottom Line, especially in the standards OHSAS 18001, ISO 26000, and SA 8000. Moreover, there is a gap considering empirical data on relating IMS impact on performance.

Implications for theory and practice: This paper contributes by proposing a conceptual model, defining the variables and presenting four relational propositions among the key variables. In a future research agenda, this study could be applied to survey-based research to answer the research propositions suggested.
\end{abstract}

Keywords

Sustainability. Integrated management system. Standard management systems. Bibliometric approach.

How to cite: Nadae, J., \& Carvalho, M. M. (2019). Integrated management systems as a driver for sustainability: the review and analysis of the literature and the proposition of the conceptual framework. Production, v28, e20180048. https://doi. org/10.1590/0103-6513.20180048

Received: June 23, 2018; Accepted: April 29, 2019

\section{Introduction}

"Sustainability has become the strategic imperative of the new millennium [...]" (Galphin \& Hebard, 2015, p. 246) and has attracted increasing attention in the academic, organizational communities and corporate spheres and can be applied in several subjects (Morioka \&t Carvalho, 2016). Its logic of interrelationship between the three pillars (social, environmental and economic) can be understood as an approach applicable in existing processes (Morioka \&t Carvalho, 2016).

Organizations began developing sustainable strategies based on the triple bottom line (TBL) to achieve improved economic, environmental, and social performance (Rocha et al., 2007), by the interaction among companies, society and the environment (Bennett \&t James, 1997). 
The TBL provides support for current decisions considering not only the usual economic factors but also the social and environmental in order to ensure the perpetuity of the enterprise. This characteristic justifies the proximity of the TBL and sustainability concepts (Nadae, 2016).

In the corporate context, Elkington (1994) reinforces the idea of "win-win-win", analyzing that strategies must be developed which are simultaneously beneficial to the company, the customer and the environment. It means that a solution to be developed considering that the company must be able to fulfill its obligations (non-negative financial result), meet the needs of impacted entities (including stakeholders such as clients, regulators, suppliers, and others) and minimize impacts (Elkington, 1994).

Measuring performance in the sustainability search has been an important issue for companies, but at the same time, it is complex. Thus, sustainability based on the TBL concept is organized into three categories: Economic, Environmental and Social (Nadae, 2016).

Integrated management systems (IMSs) can be a path for inducing sustainability (Merlin et al., 2012) mainly because manufacturing companies have undergone significant changes in the last few decades. They are now required to offer customized products, reduce product life cycles and develop sustainable production processes, all as international competition continues to increase (Gomes et al., 2006; Anholon et al., 2018).

The economic, environmental, social and corporate governance integration (Hřebíček et al. 2011, 2012), and corporate social responsibility standards have created an umbrella for voluntary social management standards, such as ISO 26000 (Mueckenberger \& Jastram, 2010; Helms et al., 2012) and SA 8000 (Reynolds \& Yuthas, 2007; Karapetrovic \&t Casadesús, 2009).

IMSs can be defined as two or more Management Systems (MSs) integrated into one. Different MSs can be implemented to achieve various goals (Tsai \&t Chou 2009). Quality Management Systems (QMS - ISO 9001), Environmental Management Systems (EMS - ISO 14001), and Occupational Health and Safety Management Systems (OH and SMS - OHSAS 18001) are the three most widely applied certifications (Lo et al., 2014).

ISO 9001 (International Organization for Standardization, 2015a) specifies Quality Management systems requirements when an organization needs to demonstrate its ability to provide products that consistently meet applicable customers, statutory and regulatory requirements. The organization that implements the 1SO 9001 requirements aims to increase customer satisfaction through effective application of the system, including processes for continuous improvement, employable at any type of organization, regardless of its type, size and the product it provides (Bonato \&t Caten, 2015).

According to Bonato \& Caten (2015) the ISO 14001 (International Organization for Standardization, $2015 \mathrm{~b}$ ) defines that international environmental management standards are intended to provide organizations with the elements of an effective Environmental Management System (EMS), which can be integrated with other management requirements, in a way to help them achieve environmental and economic goals previously determined by them. The standard specifies the requirements of an EMS, having been written to be applicable to all types of organization, of all sizes, and to suit different geographical, cultural and social conditions.

To Corrêa (2004) and Bonato \& Caten (2015) the OHSAS 18001 defines the Organizational Safety and Health Management System (OSHMS) requirements and has been drafted in such a way as to be applied to all companies, and to suit different geographical, cultural and social conditions. Such a system enables the organization to establish and evaluate the effectiveness of the procedures for defining the OSH policy and objectives, to achieve compliance with them and to demonstrate them to third parties.

These MSs present similar management principles and techniques that can be implemented jointly with the aim of obtaining quality in the production processes, producing without harming the environment, promoting sustainable development and being concerned with the quality of employees (Asif \& Searcy, 2014; Windolph \& Schaltegger, 2014). As well as to reduce pathologies and accidents, to increase organizational performance, to offer the possibility to develop, implement, organize, coordinate and monitor organizational activities and to improve the institutional image (Nadae, 2016).

The growing number of MSs represents a critical research issue because integration is particularly relevant to "[...] competitiveness, development, and sustainable success of organizations [...]" (Rebelo et al., 2016, p. 98).

The ISO (International Organization for Standardization, 2015a) also suggest that the MSs can help organizations to improve its overall performance and provide a sound basis for sustainable development initiatives.

Other authors suggested studying the integration of standards and their impact on companies' financial and environmental performance (Corbett \& Kirsch, 2004; Jacobs et al., 2010; Melnyk et al., 2003a; Zailani et al., 2012). Delmas \&t Blass (2010) propose a study on how standards encourage sustainability initiatives in organizations.

The literature suggests, "[...] most scholars seem to agree that the best way for business to contribute to sustainable development is to integrate their different management systems" (Siva et al., 2016, p. 53). Thus, 
it can be an opportunity for increasing competitive advantages and contributing to organizations' sustainable development (Jørgensen et al., 2006; Zeng et al., 2010b). However, there is a need for further studies on an in-depth understanding of the relationship between IMS and performance, which has motivated this study on how to integrate sustainability into the day-to-day operations in the mainstream business management systems (Asif et al., 2010), being still a challenge that most companies face in practice.

Other authors have also studied the relationship between IMS (mainly incorporating ISO 9001, ISO 14001 , OHSAS 18001, SA 8000, or ISO 26000) and sustainability, confirming that the implementation of ISO standards can contribute to sustainable success (Hřebíček et al., 2011, 2012; Merlin et al., 2012). According to Ferreira \&t Gerolamo (2016) some organizations are implementing Management Systems certifications to become sustainable and to satisfy the stakeholders.

The ISO 26000 is a guideline and voluntary standard; is not intended or appropriate for certification purposes. NBR 16001 is a standard auditable management system that is structured into certifiable requirements, allowing the organization to seek certification by a third party, which does not occur with 15026000 which is a guideline standard (International Organization for Standardization, 2012).

The ISO 16001 establishes minimum requirements related to a Social Responsibility Management System (SGRS), allowing the organization to formulate and implement a policy and establish objectives that take into account the legal requirements, its ethical commitments and its concern with the promotion of citizenship and sustainable development, in addition to the transparency of its activities (International Organization for Standardization, 2012).

The SA 8000 is an international standard with the aim of improving the work environments and conditions of the global workforce, requiring companies to assume responsibilities related to environmental and social interests (Social Accountability International, 2014).

SA 8000 was created in an attempt to provide definitions, standards and management systems to deal with workers' rights, as these issues had not yet been addressed by an auditable standard (Social Accountability International, 2014).

IMS as a sustainable strategy success can contribute to continuous improvement, increasing competitive advantages, opportunities to improve relationships with stakeholders, opportunities for businesses to be more competitive and finally improving organizational performance (Jørgensen et al., 2006; Jørgensen, 2008; Zeng et al., 2010b; Rebelo et al., 2014).

Many of the studies presented above identify the research gap on the IMS field as a driver for sustainability; the relationship between IMS and performance from the TBL perspective is a significant gap. To bridge this research, this paper aims to analyze the literature on standard management systems (ISO 14001, OHSAS 18001, SA 8000, and ISO 26000), and to propose a conceptual framework relating these standards to sustainability (based on TBL).

For this, the systematic literature review and bibliometric analysis are applied, social network analysis and content analysis as well. This process seeks to identify the principal topics discussed in the area, the trends and gaps in the literature, and the main authors and works. A conceptual model is presented linking the main constructs, variables, and their relations to better understand the role of IMS as a driver for sustainability.

This paper contains six sections. The research design, detailing the research protocol concerning the sample selection and the methods applied are presented in section 2 . In section 3, the results are presented, and the discussion and research conclusions correspond to sections 4 and 5, respectively.

\section{Research setting}

Due to the research objective, a systematic literature review (SLR) was the research approach selected, to help to answer the following research question: How does the literature address IMS and sustainability based on TBL? The SLR transparent and replicable procedures were organized at each step of the research protocol (Littell et al., 2008), following three steps: data collection, data analysis and synthesis (Tranfield et al., 2003).

SLR can combine multi-methods such as the bibliometric analysis, meta-analysis, and content analysis (Carvalho et al., 2013). The theoretical framework scope was based on content analysis, whose key activities are: universe definition and sample and coding and interpretation of results (Martens et al., 2013). Already through the bibliometric analyses, it is possible to visualize the relevance and the impact of themes, articles, authors and sources in the literature, as well as mapping the relationship and inter-relation between the studied elements (Carvalho et al., 2013) 
The data collection step was conducted between March until June 15th 2017 in the ISI Web of Science (WoS) database searching papers using several search strings. The WoS, due to its high relevance in the academic field, to offer differential data treatment options, and for having a significant impact on project management literature (Franco et al., 2017).

The search strings for ISO 14001 were the following: "iso 14000" or "iso 14.000" or "iso 14001" or "iso 14.001" or "iso14000" or "iso14.000" or "iso14001" or "iso14.001". Similar search strings were applied to 1S0 26000, OHSAS 18001 e SA 8000, Table 1. Then each search resulted in a database that was analyzed together (final database $=1,010$ papers, summing up all the searches) and later analyzed individually.

Table 1. The steps for the final database.

\begin{tabular}{|c|c|c|}
\hline Topic & $\begin{array}{l}\text { "iso } 14000 \text { " or "iso } 14.000 \text { " or "iso } 14001 \text { " or "iso } 14.001 \text { " or "iso } 14000 \text { " or "iso } 14.000 \text { " or } \\
\text { "iso } 14001 \text { " or "iso } 14.001 \text { " }\end{array}$ & 1486 \\
\hline Web of Science Category & $\begin{array}{l}\text { Environmental Science or Engineering Environmental or Management or Environmental Studies or Business } \\
\text { or Research Management Science or Economics or Engineering Manufacturing }\end{array}$ & \multirow{3}{*}{853} \\
\hline Type of document & Article & \\
\hline Language & English or Portuguese & \\
\hline Topic & $\begin{array}{c}\text { “ohsas } 18000 \text { " or "ohsas } 18.000 \text { " or “ohsas } 18001 \text { " or "ohsas } 18.001 \text { " or "ohsas } 18000 \text { " or } \\
\text { "ohsas } 18.000 \text { " or "ohsas } 18001 \text { " or "ohsas } 18.001 \text { " }\end{array}$ & 147 \\
\hline \multicolumn{3}{|l|}{ Web of Science Category } \\
\hline Type of document & Article & \multirow[t]{2}{*}{82} \\
\hline Language & English or Portuguese & \\
\hline Topic & “iso 26000 " or “iso 26.000 " or “iso 26000 ” or “iso 26.000 " & 89 \\
\hline \multicolumn{3}{|l|}{ Web of Science Category } \\
\hline Type of document & Article & \multirow[t]{2}{*}{47} \\
\hline Language & English or Portuguese & \\
\hline Topic & "sa 8000 " or "sa 8.000 " or "sa 8000 " or "sa8.000" & 86 \\
\hline \multicolumn{3}{|l|}{ Web of Science Category } \\
\hline Type of document & Article & \multirow[t]{2}{*}{28} \\
\hline Language & English or Portuguese & \\
\hline Final database & & 1,010 \\
\hline
\end{tabular}

Table 1 shown the filters and the number of articles withdrawn or added in each criterion (web of science category, type of document, language) for the final database construction. For each string selection criteria (ISO 14000; OHSAS 18000; ISO 26000; SA 8000) was selected only articles (type of document), reducing the number of papers found. The following criterion was only English or Portuguese papers (language), also reducing the number of papers. So finally, just for the ISO 14000 search, we selected the papers from specific research areas, as highlighted above.

The core management systems standards for this study were the ISO 14001, OHSAS 18001, ISO 26000, and SA 8000 standards that were selected to compose the MSs and analyzed as integrated standards.

A search using strings related to the ISO 9001 or ISO 9000 was performed, resulting in 3,288 papers; however, most of them are not related to IMSs and were not explicitly related to TBL perspective, because of this they were excluded. Also another search was also performed using the same search criteria for ISO 16001, and as a result it was obtained 24 articles, only 15 in English, but after reading the 15 articles it was identified that they were not relevant and that they were not related to other standards or related to TBL perspective, therefore, they were also excluded from the final sample.

In this context, the ISO 14001 search is essential to capture all possible integration with other standards because it is the most studied and applied by companies, excluding ISO 9001. Thus, the network analysis of this sample is the core to understanding the IMS cluster in the papers.

Also, the journal's relevance was analyzed, considering the journal impact, besides the total citation, or yearly average citation counting, because it "[...] can change the position of one paper in the ranking of citations [...]" (Carvalho et al., 2013, p. 1421). That is why it was calculated the papers impact index and the Author Impact Factor (AIF) according to Yearly average Citation and Journal Citation Reports Impact Factor (JCRIF) of the sample as shown in the Equation 1.

$\mathrm{AIF}=$ Yearly average Citation $*(1+\mathrm{JCRIF})$ 
With the WoS selected database, it has been analyzed the publication's evolution, main research fields of papers, main journal and most cited papers. After screening the studies and doing the data analysis step, the process of merging bibliometrics and content analysis was conducted. Thus, content analysis was chosen to analyze all the papers on these standards. Finally, the third step, SLR synthesis, was also performed. The SLR synthesis is the step that adds the most value to research, creating new knowledge based on complete data collection and meticulous analysis (Crossan \& Apaydin, 2010). After the SLR we propose a conceptual framework.

\section{Result and discussion}

\subsection{Research and literature analysis}

According to the sample surveyed, the ISO 14001 and ISO 26000 integration is the most studied frequently standard integration considered in the studies (Figure 1).

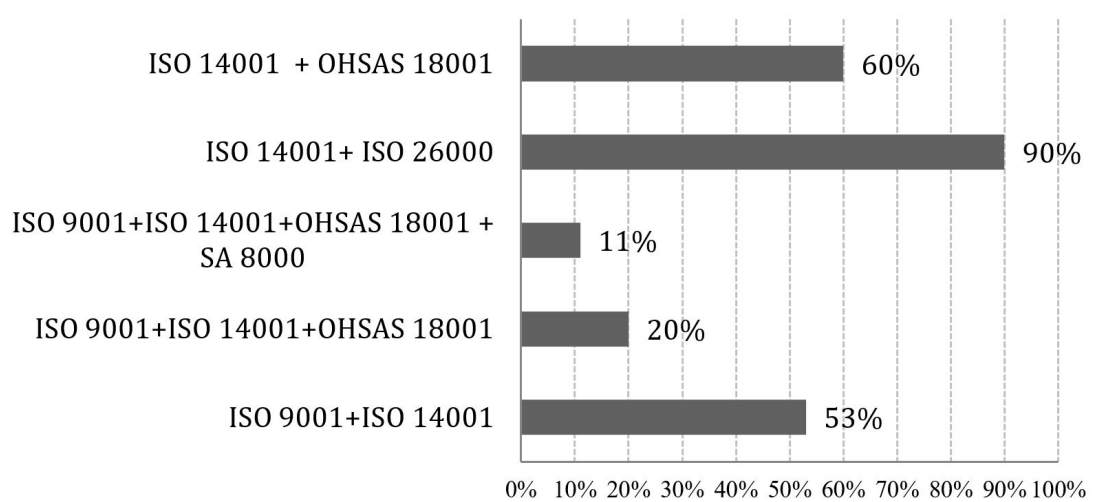

Figure 1. The frequency of standards integrated from the selected database.

Figure 2 shows that the first paper (about ISO 14001) appears in the year of 1994. Publications from 2001 and 2013 subjects are about motivations, impacts, difficult to EMS or ISO 14001 implementation in specific countries such as Japan, China, Spain, Hong Kong, Italia, Australia, Canada and others, also in this year more than 5 papers connected ISO 14001 with ISO 9001 or Total Quality Management.

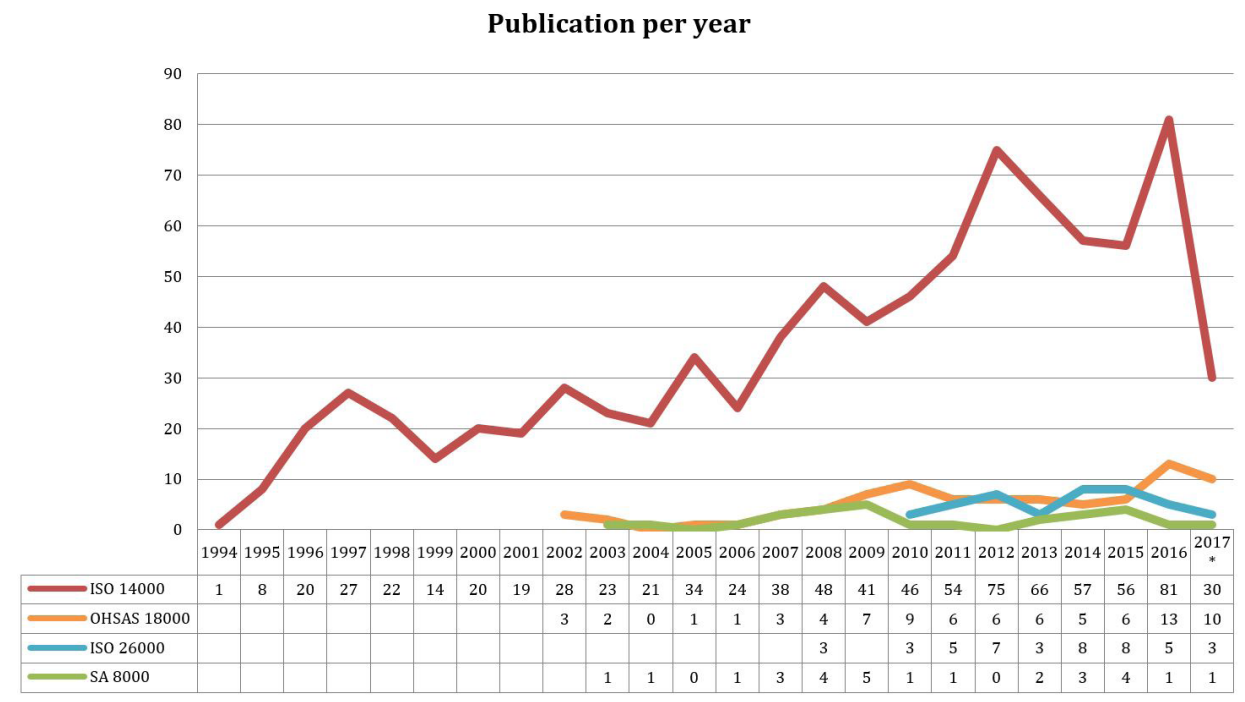

Figure 2. Evolution of the publications on ISO 14000, OHSAS 18000, ISO 26000 and SA 8000 throughout 1994-June 15 $5^{\text {th }}$, 2017 according to the WoS database (Web of Science, 2017). 
Publications from 2007 to 2012 were focused on IMS, highlighting quality management systems and environmental management systems, and studies on the ISO 14001 standard analyzing the organizational performance. Besides, in 2013 the issues were focused on sustainability, performance sustainability, and ISO 14001.

The years 2015 and 2016 publications focused on the relationship between the ISO 14000 and sustainability, the ISO 14001 benefits and ISO 9001 comparison, and the analysis of the financial investment of IMS.

Publications on OHSAS 18001 appear in the year of 2002. The topics addressed included integration of OHSAS 18001 and ISO 9001, ISO 14001, and/or SA 8000, mainly in 2016, the studies were on green manufacturing, quality management tools and OHSAS 18001.

The first publication on 1S0 26000 appears in 2008, these studies analysis social responsibility development measures in small- stakeholders influence in implementing social responsibility initiatives and the importance of integrating these actions into organizational processes were analyzed in the year of 2016.

About SA 8000 the first paper that appears in the year of 2003 was about SA 8000 and 1S0 9001, 1SO 14001, OHSAS 18001 integration and also analysis of corporate social responsibility actions in different sectors. The publications in 2009 were on the relationship of SA 8000 with the themes of sustainability, ISO 14001 certification, supplier analysis, and supply chain.

According to the database, each standard (ISO 14001, ISO 26000, OHSAS 18001 and SA 8000) present papers that study the relationship between each standard and sustainability actions based on TBL.

The research fields with the most significant number of papers (Figure 3) are Environmental Sciences, Ecology; Engineering; Business Economics; and Science Technology.

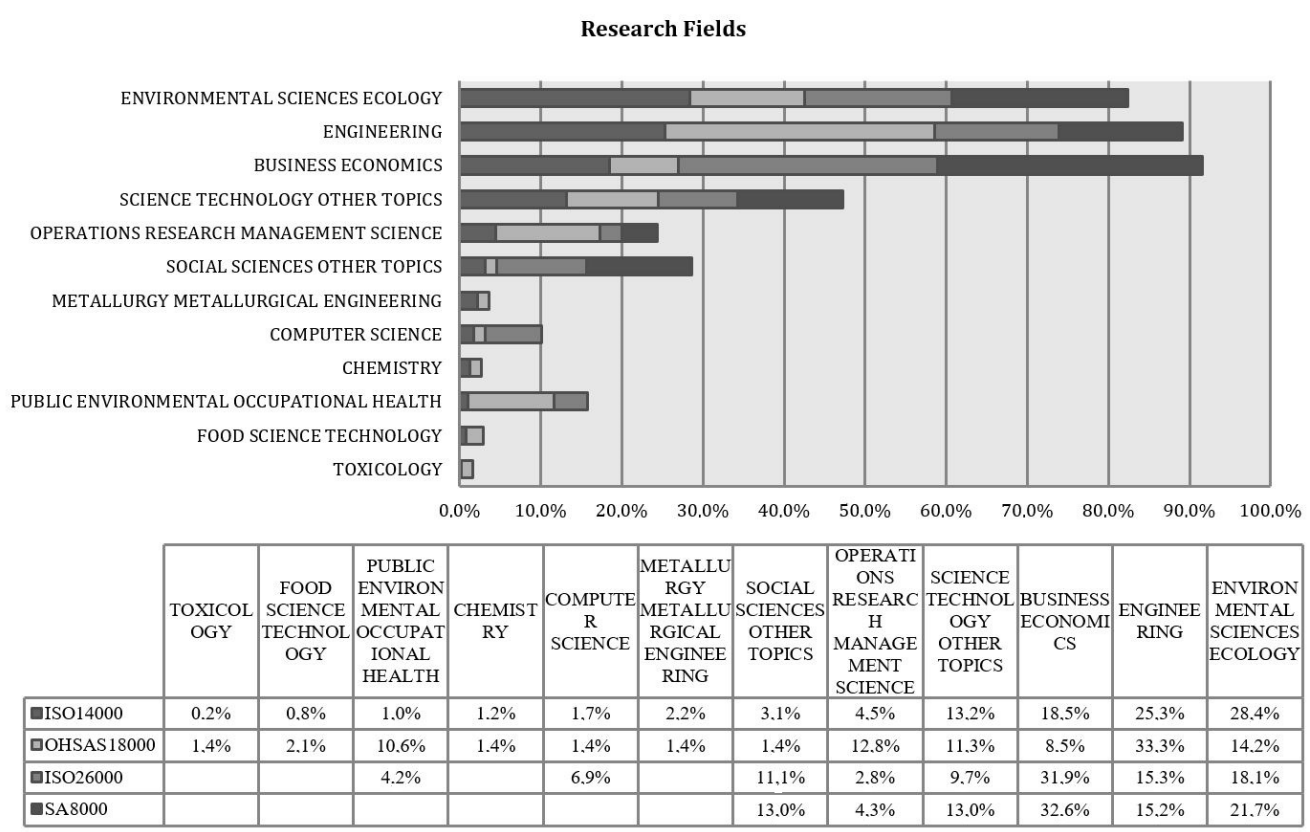

Figure 3. Research areas where papers were published on ISO 14000, OHSAS 18000, ISO 26000 and SA 8000 according to the WoS database (Web of Science, 2017).

For the most cited journal analysis on each standard, the AIF (Equation 1) was calculated to analyze the journals relevance evaluation, considering the journal impact, besides the total citation, or yearly average citation for each database Table A1, Table A2, Table A3 and Table A4 shown in Appendix A.

According to Table $A 1$, the most cited paper has 411 citations with the highest number of citations from 2013 to 2015, also corresponding to the most annual citations. The paper by (Kleindorfer et al., 2005) focuses on sustainability based on TBL perspective. On the other hand, considering the AIF the most outstanding paper is (Sarkis et al., 2010), which examines ISO 9000 and ISO 14000 as an empowerment of all employees, particularly in response to stakeholder pressure.

Delmas (2002) analyzes the rates of ISO 14000 adoption. Robèrt et al. (2002) considers ISO 14001 as one of the tools for management and monitoring of sustainable development (Melnyk et al., 2003b) analyzes the 
impact of ISO 14001 on corporate and environmental performance. Hillary (2004) evaluates the implementation of ISO 14001 in small companies. Potoski \& Prakash (2005) analyse ISO 14001 and company performance.

King et al. (2005) study ISO 14001 and ISO 9001 as competitive strategies. Sarkis (1998) evaluates the environmental awareness of organizations by their business practices. King \& Lenox (2001) conduct a study of lean production and the environmental performance of companies. Melnyk et al. (2003a) analyzes the impact of ISO 14001 on corporate and environmental performance.

About the OHSAS 18000 database is shown in Table A2, the journal that was out considering publications number was also the Journal of Cleaner Production. This database search presents many papers related to IMS. Tsai \& Chou (2009) study how the ISO 9001, ISO 14001, OHSAS 18001, and SA 8000 standards can provide competitive advantages to small and medium-sized enterprises. For Jørgensen et al. (2006), the goal is to analyze IMS (ISO 9001, ISO 14001, OHSAS 18001, and SA 8000) and the influence of organizational culture on continuous performance improvement by Danish and Spanish companies.

Additionally, Salomone (2008) analyzes the motivations of companies in implementing IMS (ISO 9001 , ISO 14001, OHSAS 18001, and SA 8000), including obstacles and external pressures. Karapetrovic Ct Casadesús (2009) develop methods and steps for the integrated implementation of the standards (ISO 9001, ISO 14001, OHSAS 18001, ISO 27001, and SA 8000).

Zeng et al. (2007) analyzes the steps in the process of integrating ISO 9001, ISO 14001, and OHSAS 18001 Oliveira Matias \& Coelho (2002) perform a study on the advantages and disadvantages of integrating ISO 9001, ISO 14001 and OHSAS 18001.

While Jørgensen (2008) emphasizes that the integration of these standards can promote sustainable development, Vinodkumar \& Bhasi (2011) analyze the implementation of workplace safety and health system in chemical industries. The implementation of ISO 9001, ISO 14001, and OHSAS 18001, the difficulties, benefits, and integration process for these standards in small and medium-sized enterprises was studied by Santos et al. (2011).

Karapetrovic \& Jonker (2003) analyzes the issue of methodology for the integration of internal, function-specific and standardized integrated management systems.

Analysis of most cited authors in literature on ISO 26000 are shown in Table A3 shows the most cited papers according to the TC and it was also calculated AIF to analyze the impact of journals in the TC. Analyzing the TC the two most cited paper was Castka \& Balzarova (2008a, b) show the social responsibility initiatives that can be obtained from ISO 9001, ISO 14001, and ISO 26000 standards and the possibilities for integration. However, the most AIF was published by Helms et al. (2012) who analyzes corporate social responsibility and the ISO 26000 standard.

Schwartz \& Tilling (2009) analyze the relationship between sustainable development, the application of ISO 14001, and the guidelines from ISO 26000 and Benoît-Norris et al. (2011) report ISO 26000 and LCA.

Balzarova \&t Castka (2012) present an empirical research on how multiple stakeholders can influence and contribute to a standard development process. Based on the analysis of comments, submitted by stakeholders, developing 15026000 standard for social responsibility.

Zenko \& Mulej (2011) analyze that ISO 26000 can increase the success of invention, innovation and diffusion processes (IIDP). The paper from Castka \& Balzarova (2008a) discuss the role of 15016000 in the adoption of social responsibility in organizations with existing quality management systems in line with ISO 9000. The authors of Colle et al. (2014) provide a constructive criticism of Corporate Social Responsibility (CSR).

SA 8000 papers are analyzed in Table A4. The paper by Tsai \&t Chou (2009) is the most cited according to citations and AIF they study how ISO 9001, ISO 14001, OHSAS 18001 e SA 8000 implementation helps to create sustainable competitive advantages.

Jørgensen et al. (2006) propose three integration levels of an integrated management system (IMS) and the relation to the learning culture and continuous improvements in this process. Additionally, Salomone (2008) analyzes the motivations of companies in implementing IMS (ISO 9001, ISO 14001, OHSAS 18001, and SA 8000), including obstacles and external pressures.

Gilbert \& Rasche (2007) focuses on a cross-cultural analysis of multinational companies with SA 8000 certification. The paper that examines corporate social responsibility (CSR) reporting, discussing models of CSR reporting and accountability: EMAS, the ISO 14000 series, SA8000, AA1000, the Global Reporting Initiative (GRI), and the Copenhagen charter is published by Reynolds \& Yuthas (2007).

Karapetrovic \&t Casadesús (2009) and Karapetrovic \&t Jonker (2003) propose methods and steps for the IMS (ISO 9001, ISO 14001, OHSAS 18001, ISO 27001, and SA 8000) implementation. 
The relationship between logistics and social responsibility is examined by Ciliberti et al. (2008) and Ciliberti et al. (2009) they analyze social responsibility in supply chain management. Rasche (2009) studies corporate social responsibility through the integration with GRl.

\subsection{Proposed framework discussion}

In the last decades, the International Organization for Standardization (ISO) has proposed and written new editions of the standards related with TBL, trying to promote some alignment among them. However, we do not find specifics studies in this database studies about the relation to IMS and TBL performance. Figure 4 summarizes the main results from the bibliometric research.

\begin{tabular}{|c|c|c|c|}
\hline ISO 14000 & OHSAS 18000 & ISO 2 & 000 \\
\hline $\begin{array}{l}\square \text { WoS n = 853 } \\
\square \text { Average citation per year : } \\
19.73 \\
\square \text { Country: United States } \\
(23.1 \%) \\
\square \text { Research field: } \\
\text { Enviornmental Sciences } \\
\square \text { Ecology ( } 28.4 \%) \\
\text { Journal: Journal of Cleaner } \\
\text { production }(20 \%) \\
\text { Topics: Sustainability; } \\
\text { environmental and } \\
\text { financial performance; } \\
\text { competitive strategies }\end{array}$ & $\begin{array}{l}\square \text { WoS n = 82 } \\
\square \text { Average citation per year: } \\
13.2 \\
\square \text { Country: China (13.8\%) } \\
\square \text { Research field: } \\
\text { Engineering (33.3\%) } \\
\square \text { Journal: Journal of Cleaner } \\
\text { production (16\%) } \\
\square \text { Topics: Influence of } \\
\text { organizational culture on } \\
\text { IMS (ISO 9000, } \\
\text { ISO14000, OHSAS } 18000 \\
\text { and SA 8000); external } \\
\text { pressures for } \\
\text { implementation of } \\
\text { standards; integration of } \\
\text { standards and sustainable } \\
\text { development }\end{array}$ & $\begin{array}{l}\square \text { WoS n }=47 \\
\square \text { Average citation per year: } \\
8.43 \\
\square \text { Country: Germany } \\
\text { (10.7\%) } \\
\square \text { Research field: Business } \\
\text { Economics ( } 31.9 \%) \\
\square \text { Journals: Journal of } \\
\text { Business ethics (13\%) and } \\
\square \text { Journal of Cleaner } \\
\text { production (13\%) } \\
\text { Topics: relation to } \\
\text { sustainable development; } \\
\text { corporate social } \\
\text { responsibility (CSR). }\end{array}$ & $\begin{array}{l}\square \text { WoS n =28 } \\
\square \text { Average citation per year: } \\
30.04 \\
\square \text { Country: Italy (25\%) } \\
\square \text { Research field: Business } \\
\text { Economics (32.6\%) } \\
\square \text { Journal: Journal of Cleaner } \\
\text { production (18\%) } \\
\square \text { Topics: sustainable } \\
\text { competitive; advantages, } \\
\text { obstacles and pressures for } \\
\text { standards }\end{array}$ \\
\hline
\end{tabular}

Figure 4. Summarize bibliometric research.

Some of the authors, such as Corbett \& Kirsch (2001), Jacobs et al. (2010), Melnyk et al. (2003b) and Zailani et al. (2012), suggest studying the integration of the standards and analysing the relationship between standards and their impact on companies' environmental and financial performance. Delmas \& Blass (2010) suggests a study on how certifications can encourage sustainability initiatives in organizations.

For Jacobs et al. (2008) and Melnyk et al. (2003a), future studies could analyze the relationship between implementing $1 \mathrm{SO}$ standards and the environmental efforts that impact companies' financial performance. In this same context, Chiang et al. (2011), Comoglio \&t Botta (2012), González et al. (2008) and Paulraj \&t Jong (2011) suggest that future studies could incorporate and analyze this relationship from the perspective of their contributions to companies' environmental performance.

ISO 14001 is a core step towards sustainability in companies, and it starts to build company policies on environment sustainability that open the organization to a broader understanding of sustainability than the economic dimension.

Furthermore, other authors study the relationship between IMS (mainly incorporating ISO 9001, ISO 14001, OHSAS 18001 and ISO 16001) and sustainability, confirming that the implementation of ISO standards may contribute to sustainable development initiatives, as shown by Merlin et al. (2012).

The studies by Jørgensen et al. (2006), Zeng et al. (2010b) conclude that the IMS is a strategy that can be considered as a continuous improvement approach that increase an organization's competitive advantage and contributes to sustainable development.

Hřebíček et al. $(2011,2012)$ analyze TBL-based indicators and apply them to the agriculture, food processing and civil construction sectors employing surveys and case studies. The studies focus on companies that, in addition to belonging to these sectors, are ISO 9001, ISO 14001, OHSAS 18001, and ISO 26000; however, the authors do not consider the integration of the standards.

As a future research agenda, it is worth considering what effective standards integration could be, concerning the number of standards integrated and/or which the best set of standards is to achieve better performance considering TBL. 
This study does not identity studies that analyze the impact of IMS on TBL-based performance, helping companies to be more sustainable. The major gap is the social perspective of TBL. The economic and environment perspectives of IMS were addressed, although only the few studies addressing to companies' performance. No papers relating IMS focus only in TBL were identified, and the social dimension remains as unaddressed research agenda.

The social dimension of TBL is not highlighted, the focus are studies on environmental dimension and economic dimension (the main word used is financial performance), so in this database the literature address IMS and sustainability the studies emphasize the importance of IMS in the company economic performance (including time to implement MSs, greater financial returns, labour optimization, improvement of company performance in the market and in the supply chain and among other factors), about company environmental performance (mitigation of environment impact, selection of suppliers with environmental certification, among other factors).

Regarding social performance, few studies analyze this aspect, mostly dealing with aspects related to workplace safety. No article in the sample reports and emphasizes, for example, the importance of IMS to the community in which the company is based or to employees in general. The ISO 26000 and SA 8000 standards are analyzed as aspect of MSs implementation as a secondary analysis and always integrated with another standard.

So, based on the literature analysis the proposed variables and propositions are shown in Figure 5.

Latent variables or construct are conceptual terms (Howell et al., 2007) that cannot be directly measured, sometimes demanding various manifest variables to translate them. The TBL-based (environmental, social, and economic) performance is assumed as the latent dependent variable in the model proposed (see Figure 5). The TBL involves the economic, social and environmental perspectives and can be designed as a first-order latent variable in two ways.

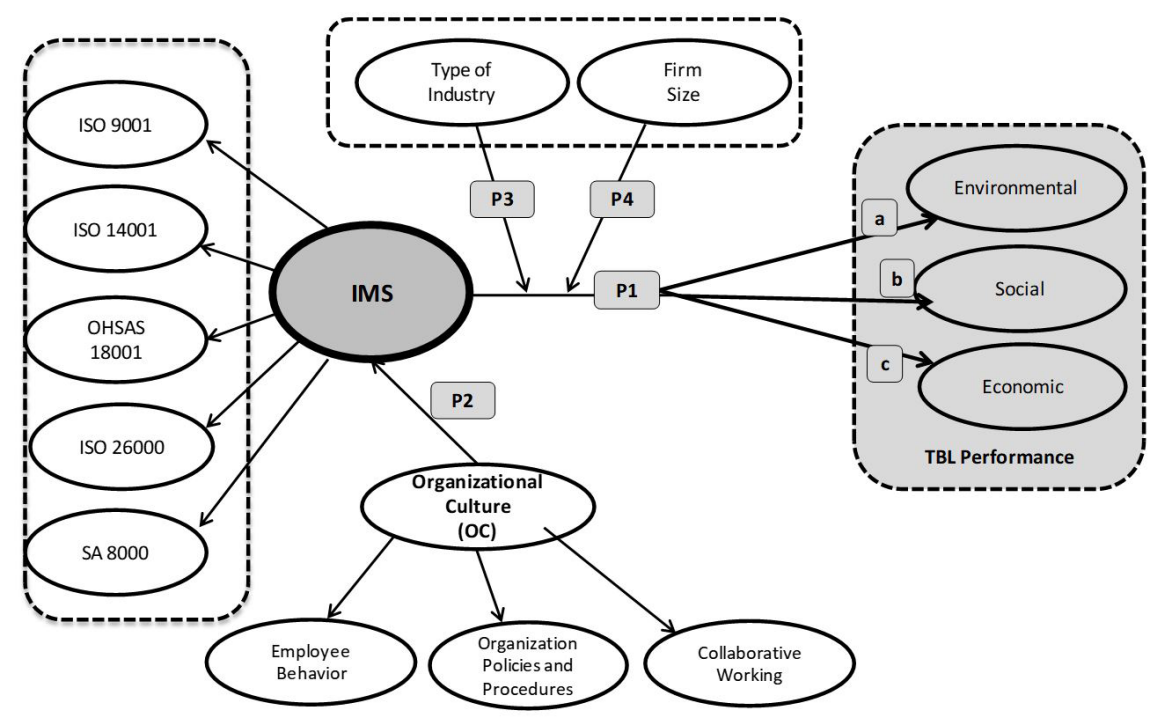

Figure 5. Conceptual Model Proposed.

It can be designed reflectively assuming that the TBL is explained by the three perspectives jointly as suggested by Hřebíček et al. (2011, 2012), Merlin et al. (2012), Zeng et al. (2010a), Jørgensen (2008) and Rocha et al. (2007). However, the TBL performance can be also studied by examining each TBL perspective. For instance, the economic perspective was explored by Melnyk et al. (2003a) and Jacobs et al. (2008), the environment perspective was explored in Chiang et al. (2011), Comoglio \& Botta (2012), Paulraj \&t Jong (2011) and González et al. (2008).

The latent independent variable is IMS, a second-order latent variable that encompasses the following first-order latent variables: ISO 9001, ISO 14001, OHSAS 18001, ISO 26000, and SA 8000. The literature surveyed that supports this understanding of the IMS construct as discussed previously BSI (British Standards Limited, 2012), Bernardo et al. (2009), Zeng et al. (2007), Seghezzi (1997), Wilkinson \& Dale (1999), Kirkby (2002), Karapetrovic (2002), Mackau (2003) and Beckmerhagen et al. (2003). This representation was applied as it is 
assumed that there is interdependence among the variables in IMS, once the standards integration is the key aspect, which can allow a reflective design of this variable.

As mentioned before, despite the lack of field research exploring the relation between IMS and TBL performance, several papers surveyed suggest propositions in this direction. From the above discussion, Proposition 1 corresponds to the main goal of the study, which is to analyze whether companies with IMS demonstrate better TBL-based performance and is formalized in the model proposed as follows:

Proposition 1 (P1) suggests that there is a significant, positive relationship between IMS and TBL-based performance. This proposition is suggested by Hřebíček et al. (2011, 2012), Merlin et al. (2012), Jørgensen (2008), Zeng et al. (2010b) and Rocha et al. (2007).

Proposition 1 can also be deployed in three propositions a, b and c, as mentioned before, related to each perspective as follows:

$\mathrm{P} 1(\mathrm{a})$ : There is a significant, positive relationship between IMS and environment performance. This proposition was pointed out Chiang et al. (2011), Comoglio \&t Botta (2012), Paulraj \&t Jong (2011) and González et al. (2008).

P1(b): There is a significant, positive relationship between IMS and social performance. Even though we could not find this proposition in the literature owing to the lack of research on this perspective, we assumed it is a reasonable relation based on the overall discussion

$\mathrm{P} 1$ (c) There is a significant, positive relationship between IMS and economic performance. This proposition was suggested by several studies, such as Melnyk et al. (2003a) and Jacobs et al. (2008).

Similar reasoning was applied to the organizational culture construct. It was designed as a second-order latent variables that encompasses the behavior of the organization's collaborators, the organization's rules and standards, and staff involvement as suggested by the literature surveyed, particularly, Watson \&t D'Annunzio-Green (1996) and Wilkinson \& Dale (1999). Based on the literature surveyed the model suggests the following proposition:

Proposition 2 (P2): Organizational culture influences the implementation of IMS.

Finally, based on the literature review we identify two moderate variables are the type of industry and firm size suggested by Karapetrovic \&t Casadesús (2009), Casadesús et al. (2007) and Nadae \&t Oliveira (2010) that can impact both the IMS and the TBL performance, suggesting the following propositions:

Proposition 3 (P3): The type of industry (sector) influences the relationship between IMS and TBL-based performance.

Proposition 4 (P4): firm size influences the relationship between IMS and TBL-based performance.

Proposition 2 analyze whether the organizational culture can influence the implementation of IMS. Propositions 3 and 4 analyzes the influence of the variables IMS and TBL-based performance on the main objective.

\section{Conclusions}

The proposed conceptual framework can help to understand the relation to IMS and sustainability considering all variables identified in the literature. Also, they can help companies to verify the impact of each MSs (implemented or will be implemented) in economic, social, environmental dimensions. Prove if MSs can help companies to be more sustainable and get sustainable performance; companies can analyze if the MSs that are already implemented impact on sustainable performance or analyze the results to decide if they want to implement MSs mainly verify the results in different firms' size and types.

This paper contributed to the literature by analyzing in depth a sample of 1,010 articles that deal with IMS (ISO 14001, OHSAS 18001, ISO 26000, and SA 8000) and TBL. Based on the analysis it was possible to answer the research question proposed, that was: How does the literature address IMS and sustainability based on TBL?

First, it shows that more research on the social dimension of TBL is needed, especially concerning standards OHSAS 18001, ISO 26000, and SA 8000, and studies on IMS and social dimension of TBL. Second the literature has still a lack considering empirical data on relating IMS and performance that allows cross-countries and cross-sectors analysis. Third it needs understanding the organizational culture and type of industry as a moderate variable between IMS and performance.

Nevertheless, a lot of research was identified to have been already conducted on ISO 9001 and ISO 14001 . This paper contributed by proposing a conceptual model and related propositions to be investigated in future empirical researches. In a future research agenda, this study could be applied to survey-based research to answer the research propositions suggested. Future studies could also: apply the model to some organizations with IMS and analyze the impact on sustainability (analysing TBL); analyze the models of IMS proposed by authors and the impact on sustainability (mainly TBL); more deeply analyze the influence or impact of organizational 
culture as a factor impacting sustainability; an analysis of IMS focusing specially on social aspects and others could emerge from the gap showed in this paper.

For managers, this study can contribute to identifying the most fragile pillar of sustainability - the social pillar. In analysing the social pillar, companies need to focus on social actions that can be developed to maintain the three pillars of sustainability. Additionally, an analysis of the impact of these standards on organizational culture can help managers holistically reflect on the impact of their implementation in organizations.

This study has limitations resulting from the research methods that rely on the ISI Web of Science for generating the initial sample, limited to number of titles; some relevant papers may thus have not been considered. These limitations were partially mitigated by the content analysis, which expanded the previous sample based on the analysis of the most cited references.

\section{Acknowledgements}

We thank the Coordenação de Aperfeiçoamento de Pessoal de Nivel Superior (CAPES - Coordination for the Improvement of Higher Education Personnel) and the Conselho Nacional de Pesquisa e Desenvolvimento (CNPq - Brazilian National Council of Scientific and Technological Development) for granting research fellowships.

\section{References}

Anholon, R., Rampasso, 1. S., Ordonez, R. E. C., Silva, D., Quelhas, O. L. G., \&t Leal Filho, W. (2018). Observed difficulties during implementation of quality management systems in Brazilian manufacturing companies. Journal of Manufacturing Technology Management, 29(1), 149-167. http://dx.doi.org/10.1108/JMTM-12-2016-0167.

Asif, M., \& Searcy, C. (2014). Towards a standardised management system for corporate sustainable development. The TQM Journal, 26(5), 411-430. http://dx.doi.org/10.1108/TQM-08-2012-0057.

Asif, M., Fisscher, O. A. M., Bruijn, E. J., \&t Pagell, M. (2010). Integration of management systems: a methodology for operational excellence and strategic flexibility. Operations Management Research, 3(3-4), 146-160. http://doi.org/10.1007/s12063-010-0037-z.

Balzarova, M. A., \&t Castka, P. (2012). Stakeholders' influence and contribution to social standards development: the case of multiple stakeholder approach to ISO 26000 development. Journal of Business Ethics, 111(2), 265-279. http://doi.org/10.1007/s10551-0121206-9.

Beckmerhagen, l., Berg, H. P., Karapetrovic, S. V., \& Willborn, W. O. (2003). Integration of management systems: focus on safety in the nuclear industry. International Journal of Quality \& Reliability Management, 20(2), 210-228. http://dx.doi.org/10.1108/02656710310456626.

Bennett, M., \& James, P. (1997). Environment-related performance measurement: current practice and trends. Ashridge: Ashridge Management College.

Benoît-Norris, C., Vickery-Niederman, G., Valdivia, S., Franze, J., Traverso, M., Ciroth, A., \& Mazijn, B. (2011). Introducing the UNEP/ SETAC methodological sheets for subcategories of social LCA. The International Journal of Life Cycle Assessment, 16(7), 682-690. http://doi.org/10.1007/s11367-011-0301-y.

Bernardo, M., Casadesus, M., Karapetrovic, S., \& Heras, 1. (2009). How integrated are environmental, quality and other standardized management systems? An empirical study. Journal of Cleaner Production, 17(8), 742-750. http://dx.doi.org/10.1016/j.jclepro.2008.11.003.

Bonato, S. V., \&t Caten, C. S. T. (2015). Diagnóstico da integração dos sistemas de gestão ISO 9001 , ISO 14001 e 0HSAS 18001. Production, 25(3), 626-640. http://dx.doi.org/10.1590/0103-6513.004811.

British Standards limited. (2012). PAS 99:2012. Publicy available specification - specification of commom management system requirement as a framework for integration (2nd ed.). London: BSI.

Carvalho, M. M., Fleury, A., \& Lopes, A. P. (2013). An overview of the literature on technology roadmapping (TRM): contributions and trends. Technological Forecasting and Social Change, 80(7), 1418-1437. http://dx.doi.org/10.1016/j.techfore.2012.11.008.

Casadesús, M., Heras, 1., \&t Karapetrovic, S. (2007). Las 9000 de la 9000: análisis del impacto de la normativa ISO 9000 en Cataluña. Barcelona: Universitat de Girona.

Castka, P., \& Balzarova, M. A. (2008a). ISO 26000 and supply chains-on the diffusion of the social responsibility standard. International Journal of Production Economics, 111(2), 274-286. http://dx.doi.org/10.1016/j.jpe.2006.10.017.

Castka, P., \& Balzarova, M. A. (2008b). The impact of ISO 9000 and ISO 14000 on standardisation of social responsibility-an inside perspective. International Journal of Production Economics, 113(1), 74-87. http://dx.doi.org/10.1016/j.jpe.2007.02.048.

Castka, P., \&t Balzarova, M. A. (2008c). Adoption of social responsibility through the expansion of existing management systems. Industrial Management \&t Data Systems, 108(3), 297-309. http://dx.doi.org/10.1108/02635570810858732.

Chiang, S.-Y., Wei, C.-C., Chiang, T.-H., \& Chen, W.-L. (2011). How can electronics industries become green manufacturers in Taiwan and Japan. Clean Technologies and Environmental Policy, 13(1), 37-47. http://dx.doi.org/10.1007/s10098-010-0284-6.

Ciliberti, F., De Groot, G., De Haan, J., \&t Pontrandolfo, P. (2009). Codes to coordinate supply chains: SMEs' experiences with SA8000. Supply Chain Management, 14(2), 117-127. http://dx.doi.org/10.1108/13598540910941984.

Ciliberti, F., Pontrandolfo, P., \& Scozzi, B. (2008). Investigating corporate social responsibility in supply chains: a SME perspective. Journal of Cleaner Production, 16(15), 1579-1588. http://dx.doi.org/10.1016/j.jclepro.2008.04.016.

Colle, S., Henriques, A., \& Sarasvathy, S. (2014). The paradox of corporate social responsibility standards. Journal of Business Ethics, 125(2), 177-191. http://dx.doi.org/10.1007/s10551-013-1912-y. 
Comoglio, C., \& Botta, S. (2012). The use of indicators and the role of environmental management systems for environmental performances improvement: a survey on ISO 14001 certified companies in the automotive sector. Journal of Cleaner Production, 20(1), 92-102. http://dx.doi.org/10.1016/j.jclepro.2011.08.022.

Corbett, C. J., Ct Kirsch, D. A. (2001). International diffusion of ISO 14000 certification. Production and Operations Management, 10(3), 327-342. http://dx.doi.org/10.1111/j.1937-5956.2001.tb00378.x.</jrn>a

Corbett, C. J., \& Kirsch, D. A. (2004). Response to "Revisiting ISO 14000 diffusion: a new "look" at the drivers of certification". Production and Operations Management, 13(3), 268-271. http://dx.doi.org/10.1111/j.1937-5956.2004.tb00511.x.

Corrêa, A. A. (2004). Avaliação de um sistema integrado de gestão: um estudo na indústria automotiva (Trabalho de Conclusão de Curso). Universidade Federal do Rio Grande do Sul, Porto Alegre.

Crossan, M. M., \& Apaydin, M. (2010). A multi-dimensional framework of organizational innovation: a systematic review of the literature. Journal of Management Studies, 476), 1154-1191. http://dx.doi.org/10.1111/j.1467-6486.2009.00880.x.

Delmas, M. A. (2002). The diffusion of environmental management standards in Europe and in the United States: An institutional perspective. Policy Sciences, 35(1), 91-119. http://dx.doi.org/10.1023/A:1016108804453.

Delmas, M., \&t Blass, V. D. (2010). Measuring corporate environmental performance: the trade-offs of sustainability ratings. Business Strategy and the Environment, 19(4), 245-260. http://dx.doi.org/10.1002/bse.676.

Elkington, J. (1994). Towards the sustainable corporation: win-win-win business strategies for sustainable development. California Management Review, 36(2), 90-100. http://dx.doi.org/10.2307/41165746.

Ferreira, C. S., \&t Gerolamo, M. C. (2016). Análise da relação entre normas de sistema de gestão (ISO 9001, ISO 14001, NBR 16001 e OHSAS 18001) e a sustentabilidade empresarial. Gestão \&t Produção, 23(4), 689-703. http://dx.doi.org/10.1590/0104-530x2525-15.

Franco, E. F., Hirama, K., \& Carvalho, M. M. (2017). Applying system dynamics approach in software and information system projects: a mapping study. Information and Software Technology, 93, 58-73. http://dx.doi.org/10.1016/j.infsof.2017.08.013.

Galphin, T., \&t Hebard, J. (2015). Sustainability in start-up ventures: what founders say versus what they do. World Journal of Enterpreneurship, Management and Sustainable Development, 11(4), 246-255. https://doi.org/10.1108/WJEMSD-05-2015-0025.

Gilbert, D. U., \& Rasche, A. (2007). Discourse ethics and social accountability: the ethics of SA 8000. Business Ethics Quarterly, 17(2), 187-216. http://dx.doi.org/10.5840/beq200717230.

Gomes, C. F., Yasin, M. M., \& Lisboa, J. V. (2006). Performance measurement practices in manufacturing firms: an empirical investigation. Journal of Manufacturing Technology Management, 17(2), 144-167. http://dx.doi.org/10.1108/17410380610642241.

González, P., Sarkis, J., \&t Adenso-Díaz, B. (2008). Environmental management system certification and its influence on corporate practices: evidence from the automotive industry. International Journal of Operations \& Production Management, 28(11), 10211041. http://dx.doi.org/10.1108/01443570810910179.

Helms, W. S., Oliver, C., \& Webb, K. (2012). Antecedents of settlement on a new institutional practice: negotiation of the 15026000 standard on social responsibility. Academy of Management Journal, 55(5), 1120-1145. http://dx.doi.org/10.5465/amj.2010.1045.

Hillary, R. (2004). Environmental management systems and the smaller enterprise. Journal of Cleaner Production, 12(6), 561-569. http:// dx.doi.org/10.1016/j.jclepro.2003.08.006.

Howell, R. D., Breivik, E., \& Wilcox, J. B. (2007). Reconsidering Formative Measurement. Psychological Methods, 12(2), 205-218. http:// dx.doi.org/10.1037/1082-989X.12.2.205. PMid:17563173.

Hřebíček, J., Popelka, O., Štencl, M., \&t Trenz, O. (2012). Corporate Performance Indicators for Agriculture and Food Processing Sector, LX(4), 121-132.

Hřebiček, J., Soukopová, J., Štencl, M., \&t Trenz, O. (2011). Integration of economic, environmental, social and corporate governance performance and reporting in enterprises. Acta Universitatis Agriculturae et Silviculturae Mendelianae Brunensis, 59(7), $157-166$. http://dx.doi.org/10.11118/actaun201159070157.

International Organization for Standardization. (2012). ISO 26000: 2012 - Guidance on Social Responsibility Geneva. Geneva: Switzerland. International Organization for Standardization. (2015a). ISO 9000:2015 - Quality Management Principles. Geneva: Switzerland; 2015. International Organization for Standardization. (2015b). ISO 14000: 2015 - Environmental Management Systems. Geneva: Switzerland.

Jacobs, B. W., Singhal, V. R., \& Subramanian, R. (2008). An empirical investigation of environmental performance and the market value of the firm (pp. 430-441). Atlanta: SSRN. http://dx.doi.org/10.2139/ssrn.1320721.

Jacobs, B. W., Singhal, V. R., \& Subramanian, R. (2010). An empirical investigation of environmental performance and the market value of the firm. Journal of Operations Management, 28(5), 430-441. http://dx.doi.org/10.1016/j.jom.2010.01.001.

Jørgensen, T. H. (2008). Towards more sustainable management systems: through life cycle management and integration. Journal of Cleaner Production, 16(10), 1071-1080. http://dx.doi.org/10.1016/j.jclepro.2007.06.006.

Jørgensen, T. H., Remmen, A., \& Mellado, M. D. (2006). Integrated management systems - three different levels of integration. Journal of Cleaner Production, 14(8), 713-722. http://dx.doi.org/10.1016/j.jclepro.2005.04.005.

Karapetrovic, S. (2002). Strategies for the integration of management systems and standards. The TQM Magazine, 14(1), 61-67. http:// dx.doi.org/10.1108/09544780210414254.

Karapetrovic, S., \&t Casadesús, M. (2009). Implementing environmental with other standardized management systems: Scope, sequence, time and integration. Journal of Cleaner Production, 17(5), 533-540. http://dx.doi.org/10.1016/j.jclepro.2008.09.006.

Karapetrovic, S., \& Jonker, J. (2003). Integration of standardized management systems: Searching for a recipe and ingredients. Total Quality Management \&t Business Excellence, 14(4), 451-459. http://dx.doi.org/10.1080/1478336032000047264.

King, A. A., \& Lenox, M. J. (2001). Lean and green? An empirical examination of the relationship between lean production and environmental performance. Production and Operations Management, 10(3), 244-256. http://dx.doi.org/10.1111/j.1937-5956.2001.tb00373.x.

King, A. A., Lenox, M. J., \& Terlaak, A. (2005). The strategic use of decentralized institutions: exploring certification with the 1S0 14001 management standard. Academy of Management Journal, 48(6), 1091-1106. http://dx.doi.org/10.5465/amj.2005.19573111.

Kirkby, A. (2002). The one-stop shop. Quality World, 14-17. 
Kleindorfer, P., Singhal, K., \&t Van Wassenhove, L. (2005). Sustainable operations management. Production and Operations Management, 14(4), 482-492. http://dx.doi.org/10.1111/j.1937-5956.2005.tb00235.x.

Littell, J. H., Corcoran, J., \&t Pillai, V. (2008). Systematic reviews and meta-analysis. New York: Oxford University Press. http://dx.doi. org/10.1093/acprof:oso/9780195326543.001.0001.

Lo, C. K. Y., Pagell, M., Fan, D., Wiengarten, F., \& Yeung, A. C. L. (2014). OHSAS 18001 certification and operating performance: The role of complexity and coupling. Journal of Operations Management, 32(5), 268-280. http://dx.doi.org/10.1016/j.jom.2014.04.004.

Maas, S., \& Reniers, G. (2014). Development of a CSR model for practice: connecting five inherent areas of sustainable business. Journal of Cleaner Production, 64, 104-114. http://dx.doi.org/10.1016/j.jclepro.2013.07.039.

Mackau, D. (2003). SME integrated management system: a proposed experiences model. The TQM Magazine, 15(1), 43-51. http:// dx.doi.org/10.1108/09544780310454448.

Martens, M. L., Brones, F., \& Carvalho, M. M. (2013). Lacunas e tendências na literatura de sustentabilidade no gerenciamento de projetos: uma revisão sistemática mesclando bibliometria e análise de conteúdo. Revista de Gestão e Projetos, 4(1), 165-195. http:// dx.doi.org/10.5585/gep.v4i1.123.

Matias, J. C. 0., \& Coelho, D. A. (2002). The integration of the standards systems of quality management, environmental management and occupational health and safety management. International Journal of Production Research, 40(15), 3857-3866. http://dx.doi. org/10.1080/00207540210155828.

Melnyk, S. A., Sroufe, R. P., \& Calantone, R. (2003a). Assessing the impact of environmental management systems on corporate and environmental performance. Journal of Operations Management, 21(3), 329-351. http://dx.doi.org/10.1016/S0272-6963(02)00109-2.

Melnyk, S. A., Sroufe, R. P., \& Calantone, R. J. (2003b). A model of site-specific antecedents of 1S0 14001 certification. Production and Operations Management, 12(3), 369-385. http://dx.doi.org/10.1111/j.1937-5956.2003.tb00209.x.

Merlin, F. K., Pereira, V. L. D. V., \& Pacheco Junior, W. (2012). Sustainable development induction in organizations: a convergence analysis of 150 standards management tools' parameters. Work (Reading, Mass.), 41(Suppl 1), 2736-2743. http://dx.doi.org/10.3233/ WOR-2012-0518-2736. PMid:22317134.

Morioka, S. N., \& Carvalho, M. M. (2016). Sustentabilidade e gestão de projetos: um estudo bibliométrico. Production, 26(3), 656-674. http://dx.doi.org/10.1590/0103-6513.058912.

Mueckenberger, U., \& Jastram, S. (2010). Transnational norm-building networks and the legitimacy of corporate social responsibility standards. Journal of Business Ethics, 97(2), 223-239. http://dx.doi.org/10.1007/s10551-010-0506-1.

Nadae, J. (2016). Sistemas de gestão integrados como indutor para a sustentabilidade: uma análise do impacto no desempenho das organizações baseado no Triple Bottom Line [Tese de doutorado]. Escola Politécnica, Universidade de São Paulo, São Paulo. http:// dx.doi.org/10.11606/T.3.2016.tde-04072016-154457.

Nadae, J., \& Oliveira, O. J. (2010). Proposta de método para introdução de práticas integradas de gestão em clusters industriais. Bauru: Universidade Estadual Paulista Julio de Mesquita Filho.

Oliveira Matias, J. C., \& Coelho, D. A. (2002). The integration of the standards systems of quality management, environmental management and occupational health and safety management. International Journal of Production Research, 40(15), 3857-3866. http://dx.doi. $\operatorname{org} / 10.1080 / 00207540210155828$.

Paulraj, A., \& Jong, P. (2011). The effect of IS0 14001 certification announcements on stock performance. International Journal of Operations \& Production Management, 31(7), 765-788. http://dx.doi.org/10.1108/01443571111144841.

Potoski, M., \& Prakash, A. (2005). Covenants with weak swords: ISO 14001 and facilities' environmental performance. Journal of Policy Analysis and Management, 24(4), 745-769. http://dx.doi.org/10.1002/pam.20136.

Rasche, A. (2009). Toward a model to compare and analyze accountability standards-The case of the UN Global Compact. Corporate Social Responsibility and Environmental Management, 16(4), 192-205. http://dx.doi.org/10.1002/csr.202.

Rebelo, M. F., Santos, G., \& Silva, R. (2014). Conception of a flexible integrator and lean model for integrated management systems. Total Quality Management \& Business Excellence, 25(5-6), 683-701. http://dx.doi.org/10.1080/14783363.2013.835616.

Rebelo, M. F., Santos, G., \& Silva, R. (2016). Integration of management systems: towards a sustained success and development of organizations. Journal of Cleaner Production, 127, 96-111. http://dx.doi.org/10.1016/j.jclepro.2016.04.011.

Reynolds, M., \& Yuthas, K. (2007). Moral discourse and corporate social responsibility reporting. Journal of Business Ethics, 78(1-2), 47-64. http://dx.doi.org/10.1007/s10551-006-9316-x.

Robèrt, K.-H., Schmidt-Bleek, B., Aloisi de Larderel, J., Basile, G., Jansen, J. L., Kuehr, R., Price Thomas, P., Suzuki, M., Hawken, P., \& Wackernagel, M. (2002). Strategic sustainable development-selection, design and synergies of applied tools. Journal of Cleaner Production, 10(3), 197-214. http://dx.doi.org/10.1016/S0959-6526(01)00061-0.

Rocha, M., Searcy, C., \& Karapetrovic, S. (2007). Integrating sustainable development into existing management systems. Total Quality Management \& Business Excellence, 18(1-2), 83-92. http://dx.doi.org/10.1080/14783360601051594.

Salomone, R. (2008). Integrated management systems: experiences in Italian organizations. Journal of Cleaner Production, 16(16), 1786-1806. http://dx.doi.org/10.1016/j.jclepro.2007.12.003.

Santos, G., Mendes, F., \& Barbosa, J. (2011). Certification and integration of management systems: the experience of Portuguese smal and medium enterprises. Journal of Cleaner Production, 19(17-18), 1965-1974. http://dx.doi.org/10.1016/j.jclepro.2011.06.017.

Sarkis, J. (1998). Evaluating environmentally conscious business practices. European Journal of Operational Research, 107(1), $159-174$. http://dx.doi.org/10.1016/S0377-2217(97)00160-4.

Sarkis, J., Gonzalez-Torre, P., \& Adenso-Diaz, B. (2010). Stakeholder pressure and the adoption of environmental practices: the mediating effect of training. Journal of Operations Management, 28(2), 163-176. http://dx.doi.org/10.1016/j.jom.2009.10.001.

Schwartz, B., \& Tilling, K. (2009). "ISO-lating” corporate social responsibility in the organizational context: a dissenting interpretation of ISO 26000. Corporate Social Responsibility and Environmental Management, 16(5), 289-299.

Seghezzi, H. D. (1997). Business concept redesign. Total Quality Management, 8(2-3), 36-43. http://dx.doi.org/10.1080/0954412979677. 
Siva, V., Gremyr, 1., Bergquist, B., Garvare, R., Zobel, T., \& lsaksson, R. (2016). The support of quality management to sustainable development: a literature review. Journal of Cleaner Production, 138, 148-157. http://dx.doi.org/10.1016/j.jclepro.2016.01.020.

Social Accountability International. (2014). SA8000 Certified Organisations. New York: SAAS.

Tranfield, D., Denyer, D., \& Smart, P. (2003). Towards a methodology for developing evidence-informed management knowledge by means of systematic review. British Journal of Management, 14(3), 207-222. http://dx.doi.org/10.1111/1467-8551.00375.

Tsai, W.-H., \& Chou, W.-C. (2009). Selecting management systems for sustainable development in SMEs: a novel hybrid model based on DEMATEL, ANP, and ZOGP. Expert Systems with Applications, 36(2), 1444-1458. http://dx.doi.org/10.1016/j.eswa.2007.11.058.

Vinodkumar, M. N., \& Bhasi, M. (2011). A study on the impact of management system certification on safety management. Safety Science, 49(3), 498-507. http://dx.doi.org/10.1016/j.ssci.2010.11.009.

Watson, S., \& D’Annunzio-Green, N. (1996). Implementing cultural change through human resources: the elusive organization alchemy? International Journal of Contemporary Hospitality Management, 8(2), 25-30. http://dx.doi.org/10.1108/09596119610111712.

Wilkinson, G., \& Dale, B. G. (1999). Models of management system standards: a review of the integration issues. International Journal of Management Reviews, 1(3), 279-298. http://dx.doi.org/10.1111/1468-2370.00016.

Windolph, S. E., \& Schaltegger, S. (2014). Implementing corporate sustainability. Sustainability accounting. Management and Policy Journal, 5(4), 378-404. http://dx.doi.org/10.1108/SAMPJ-01-2014-0002.

Web of Science. (2017). WoS database. Retrieved in 15 June 2017, from Retrieved from https://login.webofknowledge.com/error/Er ror?Error=IPError\&Pathlnfo=02F\&RouterURL=https\%3A\%2F\%2Fwww.webofknowledge.com\%2F\&Domain=.webofknowledge. com\&Src $=$ IP\&Alias $=$ WOK5

Zailani, S. H. M., Eltayeb, T. K., Hsu, C.-C., \& Tan, K. C. (2012). The impact of external institutional drivers and internal strategy on environmental performance. International Journal of Operations \& Production Management, 32(6), 721-745. http://dx.doi. org/10.1108/01443571211230943.

Zeng, S. X., Shi, J. J., \& Lou, G. X. (2007). A synergetic model for implementing an integrated management system: an empirical study in China. Journal of Cleaner Production, 15(18), 1760-1767. http://dx.doi.org/10.1016/j.jclepro.2006.03.007.

Zeng, S. X., Tam, C. M., \& Tam, V. W. Y. (2010a). Integrating safety. Environmental and Quality Risks for Project Management Using a FMEA Method, $21(1), 44-52$.

Zeng, S. X., Tam, V. W. Y., \& Le, K. N. (2010b). Towards Effectiveness of Integrated Management Systems for Enterprises, 21(2), $171-179$.

Zenko, Z., \& Mulej, M. (2011). Diffusion of innovative behaviour with social responsibility. Kybernetes, 40(9-10), 1258-1272. http:// dx.doi.org/10.1108/03684921111169378. 
Appendix A. Analyzes of the most cited authors by standards (ISO 14000, OHSAS 18000, ISO 26000, SA 8000).

Table A1. Analysis of most cited authors in literature on ISO 14000 (International Organization for Standardization, 2015b) (Based on the WoS data resulting from the search) (Web of Science, 2017).

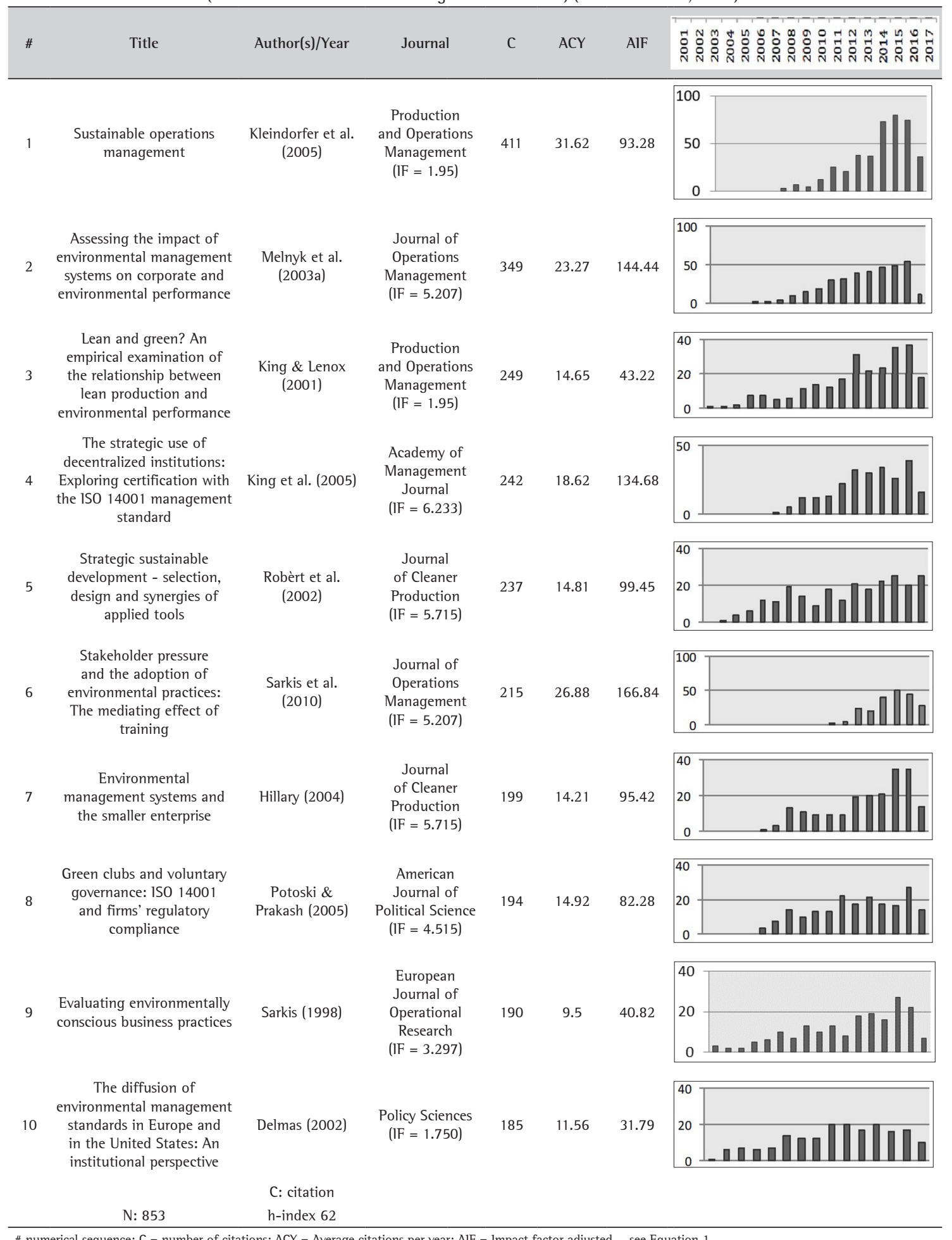

\# numerical sequence; $\mathrm{C}=$ number of citations; $\mathrm{ACY}=$ Average citations per year; $\mathrm{AlF}=$ Impact factor adjusted - see Equation 1. 
Table A2. Analysis of most cited authors in literature on OHSAS 18000 (Based on the WoS data resulting from the search) (Web of Science, 2017).

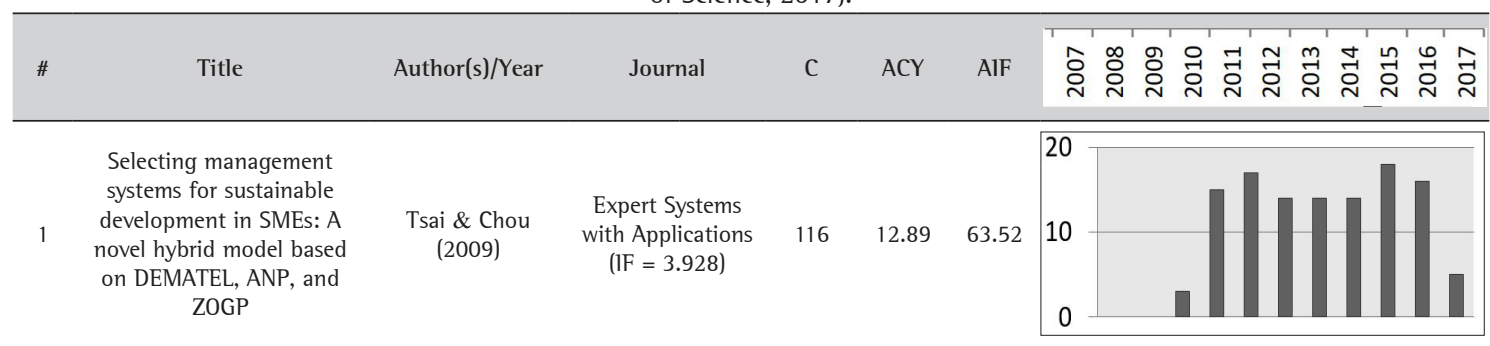

\section{Integrated management 2 systems - three different levels of integration}

A synergetic model for 3 implementing an integrated management system: an empirical study in China

Integrated management 4 systems: experiences in ttalian organizations

Implementing environmental with other 5 standardized management systems: Scope, sequence, time and integration

Certification and integration of management

6 systems: the experience of Portuguese small and medium enterprises

Towards more sustainable management systems:

7 through life cycle management and integration

Integration of standardized management systems: searching for a recipe and ingredients

The integration of the standards systems of quality management, environmental management and occupational health and safety management

A study on the impact of management system certification on safety management

\section{Jørgensen et al. (2006)}

Zeng et al. (2007)

of Cleaner

Production

$(\mathrm{IF}=5.715)$

Journal

of Cleaner

Production

$(\mathrm{IF}=5.715)$

Journal

Karapetrovic \&

Casadesús (2009)

of Cleaner

Production

$(\mathrm{IF}=5.715)$

Journal

Santos et al.

(2011)

of Cleaner

Production

$(\mathrm{IF}=5.715)$

Journal

of Cleaner

Jørgensen (2008)

Production (1F =

5.715)

Total Quality

Management

Karapetrovic \&

Jonker (2003)

\& Business

Excellence

$(\mathrm{IF}=0.896)$

International

Journal of

Matias \& Coelho (2002)

Production
Research

$(\mathrm{IF}=2.40)$

Vinodkumar \& Safety Science

Bhasi (2011)
85

7.08

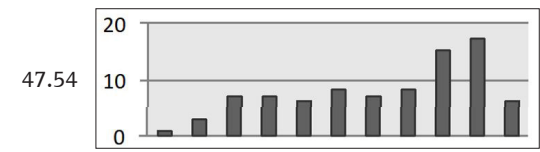

84

7.64

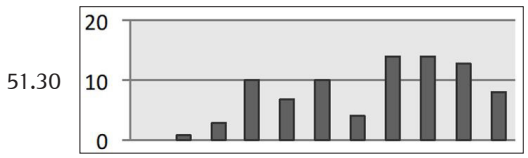

81

8.1

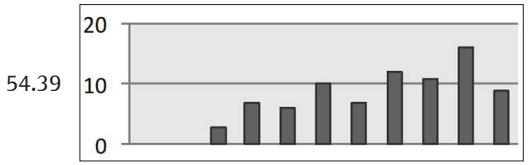

65

7.22

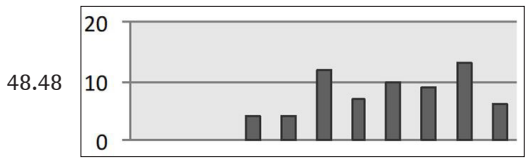

48

6.86
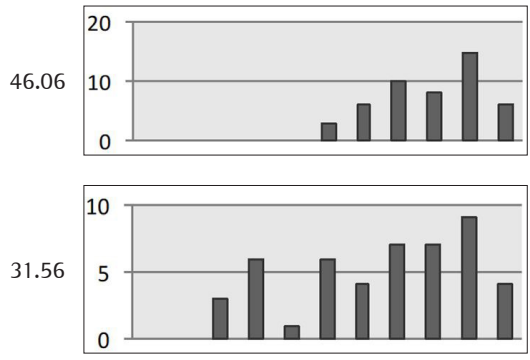

47

3.13

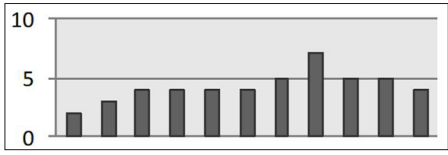

45

2.81

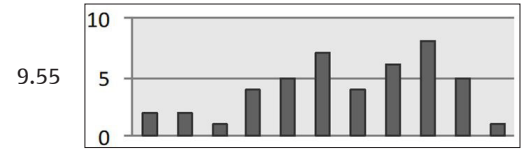

34

34

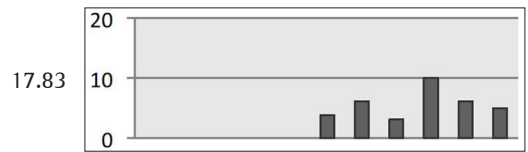

C: citation

$\mathrm{N}: 82$

h-index 17

\# numerical sequence; $\mathrm{C}=$ number of citations; $\mathrm{ACY}=$ Average citations per year; $\mathrm{AlF}=1 \mathrm{mpact}$ factor adjusted - see Equation $1 ; \mathrm{IF}=1 \mathrm{mpact}$ Factor; $\mathrm{N}=$ number of papers; h-index $=$ is an author-level metric that attempts to measure both the productivity and citation impact of the publications of a scientist or scholar. 
Table A3. Analysis of most cited authors in literature on ISO 26000 (International Organization for Standardization, 2012) (Based on the WoS data resulting from the search) (Web of Science, 2017).

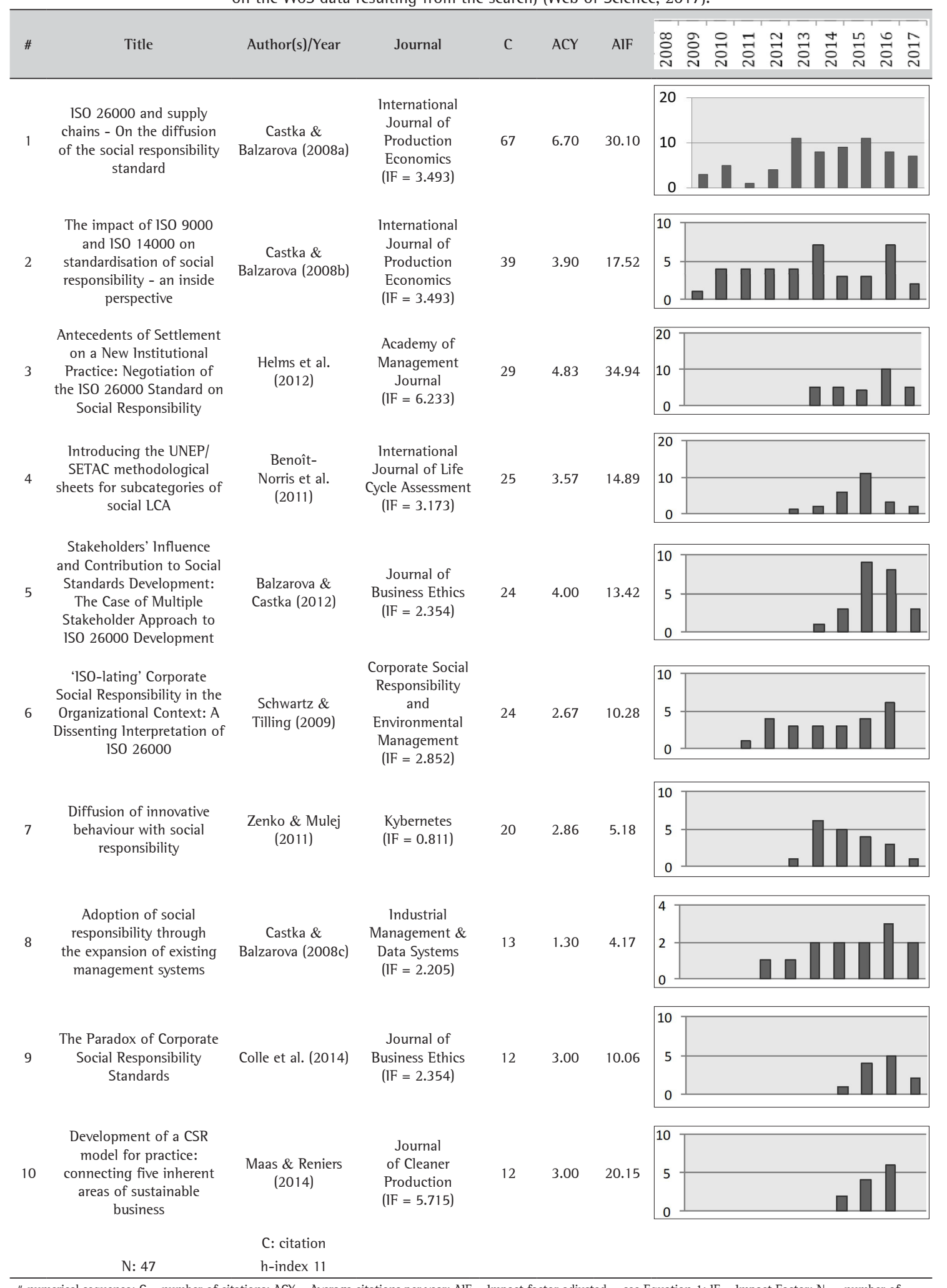

\# numerical sequence; $\mathrm{C}=$ number of citations; $\mathrm{ACY}=$ Average citations per year; $\mathrm{AIF}=$ Impact factor adjusted - see Equation $1 ; \mathrm{IF}=1 \mathrm{mpact}$ Factor; $\mathrm{N}=$ number of papers; h-index $=$ is an author-level metric that attempts to measure both the productivity and citation impact of the publications of a scientist or scholar. 
Table A4. Analysis of most cited authors in literature on SA 8000 (Social Accountability International, 2014) (Based on the WoS data resulting from the search) (Web of Science, 2017).

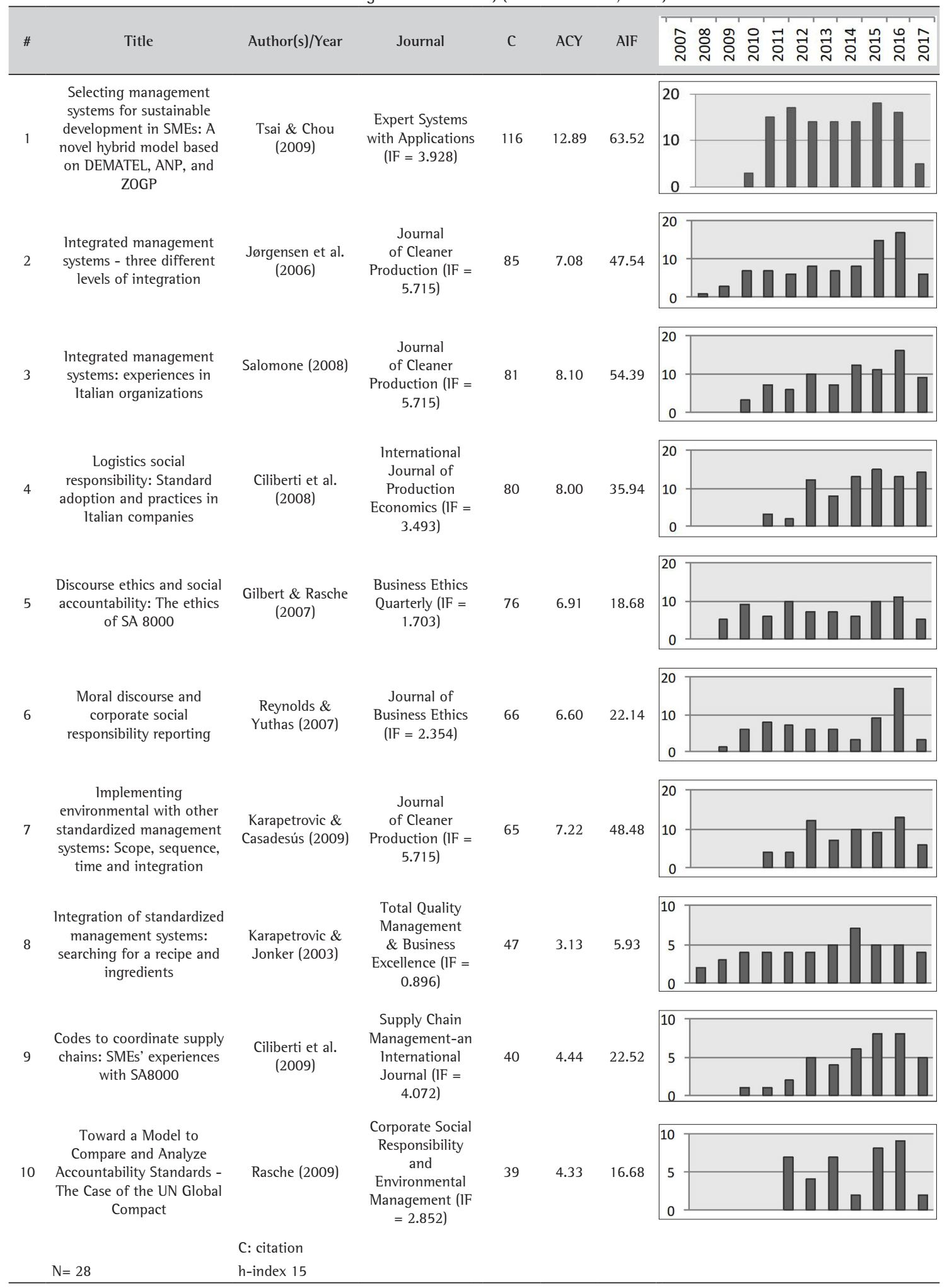

\# numerical sequence; $\mathrm{C}=$ number of citations; $\mathrm{ACY}=$ Average citations per year; $\mathrm{AlF}=$ Impact factor adjusted - see Equation $1 ; \mathrm{IF}=\mathrm{Impact}$ Factor; $\mathrm{N}=$ number of papers; $\mathrm{h}$-index $=$ is an author-level metric that attempts to measure both the productivity and citation impact of the publications of a scientist or scholar. 